\title{
Identification of a Novel Gene, Slc39a8, Encoding Zinc Transporter Specific to Treg Cells by Integrative Bioinformatic Analysis and Its Functional Validation
}

\author{
Dong Woo Ko ${ }^{1}$, Jeesang Yoon ${ }^{2}$, Jung Jin Yang, ${ }^{1}$ * \\ ${ }^{1}$ School of Computer Science and Information Engineering, The Catholic University of Korea, Bucheon, South Korea \\ ${ }^{2}$ Department of Biotechnology, Yonsei University, Seoul, Korea
}

Email address:

koodoowoo@naver.com (D. W. Ko), jeesang0328@naver.com (J. Yoon), jungjin@catholic.ac.kr (J. J. Yang)

*Corresponding author

To cite this article:

Dong Woo Ko, Jeesang Yoon, Jung Jin Yang. Identification of a Novel Gene, Slc39a8, Encoding Zinc Transporter Specific to Treg Cells by Integrative Bioinformatic Analysis and Its Functional Validation. Computational Biology and Bioinformatics. Vol. 7, No. 2, 2019, pp. 22-29. doi: $10.11648 /$ j.cbb. 20190702.12

Received: November 21, 2019; Accepted: December 9, 2019; Published: January 4, 2020

\begin{abstract}
Regulatory $\mathrm{T}$ cell (Treg cell) is a subset of $\mathrm{T}$ cell expressing Foxp3 transcription factor and critical for maintaining the immunological homeostasis in autoimmune micro-environment. However, the absence of the surface marker specific to Treg cell is the major barrier for the development of therapeutic reagent targeting Treg cells. To identify a novel gene specific to Treg cells mRNA sequencing data about naïve $\mathrm{T}$ cell, activated $\mathrm{T}$ cells $(\mathrm{Th} 0), \mathrm{T}_{\mathrm{H}} 1$ and Treg cells were processed by integrative bioinformatic methods and 350 Differentially Expressed Genes (DEGs) specific to Treg cells were selected. Using the bioinformatic program to score the intracellular location and functional gene network analysis to measure the functional relationship to Foxp3 Slc39a8 gene encoding zinc transport on the surface of Treg cells was chosen as a final candidate. The protein expression of the Slc39a8 gene was highly specific to Treg cells among various $\mathrm{T}$ cell subsets, and its expression was induced by TGF- $\beta$. In a dose-dependent manner, which is the key immuno-suppressive cytokine. The immuno-suppressive capacity of $\mathrm{CD}^{+} / \mathrm{Slc} 39 \mathrm{a} 8^{+} \mathrm{T}$ cells toward the activated $\mathrm{T}$ cells was substantially higher than that of $\mathrm{CD}^{+} / \mathrm{CD} 25^{+} \mathrm{T}$ cells in a contact-independent way. Taken these results together, Slc39a8 was identified as a novel Treg cell-specific marker encoding a zinc transporter on the surface, which is functionally important for Treg cells. Therefore, Slc39a 8 will serve as a new target molecule to develop the therapeutics for the treatment of various autoimmune diseases and solid cancers.
\end{abstract}

Keywords: Regulatory T Cells, Integrative Bioinformatics, DEG, Functional Gene Network, Slc39a8, Immunosuppression

\section{Introduction}

Regulatory T cell (Treg cell) is a T cell subset capable of suppressing immune responses, thereby maintaining immune homeostasis. Treg cells are characterized by the expression of the transcription factor Foxp3, which is known to be critical for the development and functions of Treg cells [1, 2]. In autoimmune patients, the reduced number or the functional defect of Treg cells is observed. However, Treg cells recruited into the tumor suppress the anti-tumor activity of effector T cells. Therefore, the functional regulation of Treg cells through the surface protein in autoimmune or tumor micro-environment is a critical element for the development of novel therapeutics [3].

Several surface proteins specific to Treg cells such as CD25, CTLA-4, CCR4, or GITR have been identified using microarray analysis or mRNA sequencing. However, the significant level of all of these proteins can also be detected on the surface of activated $\mathrm{T}$ cells so that the reagents targeting these surface proteins may have a limited therapeutic efficacy [4-7]. Therefore, it is essential to identify the gene whose expression is highly specific to Treg cells, but relatively low in other $T$ cell subsets.

To identify the novel gene encoding the surface protein specifically expressed on the surface of Treg cells, not of other $\mathrm{T}$ cell subsets the read count of mRNA sequencing data 
about naive $\mathrm{T}$ cells, activated $\mathrm{T}$ cells $(\mathrm{Th} 0), \mathrm{T}_{\mathrm{H}} 1$ and Treg cells was converted into the normalized Transcripts Per Million (TPM) value. It is because the length of each mRNA aligned to its DNA sequence is different. Among 12,744 genes, Differentially Expressed Genes (DEG) with top 350 rankings with regard to the specificity to Treg cells over Th0 cells were selected. Then, the intracellular localization of these genes and their functional relationship to Foxp3 was analyzed to choose the gene encoding the surface protein. Slc39a8 gene encoding zinc transporter was selected as a final candidate gene. The expression specificity of Slc39a8 protein was compared among various $\mathrm{T}$ cell subsets, and its functions in Treg cells was confirmed using in vitro suppression assay. In conclusion, the results from this study suggest that $\operatorname{Slc} 39 \mathrm{a} 8$ is a novel surface protein functionally important for Treg cell and will be a novel target molecule to develop the new therapeutics for autoimmune or solid cancer patients.

\section{Materials and Methods}

\subsection{Database}

mRNA sequencing data about mouse naïve $\mathrm{T}$ cells, Th0, $\mathrm{T}_{\mathrm{H}} 1$ and Treg cells were available from Genomic Database, Gene Expression Omnibus (GEO).

\subsection{Conversion of Raw Data into TPM Value}

Kallisto [8] was used to align the sequence reads to transcriptome database. Kallisto uses de Bruijn Graphs [9] to construct its index as shown in Figure 1 and does a pseudoalignment on the graph to quickly align the sequence to the transcriptome during the alignment phase. Each node in the graph represents k-mers, which are sequences of base pairs. Kallisto provides pre-built indexes based on the hg38 human reference genome [10].

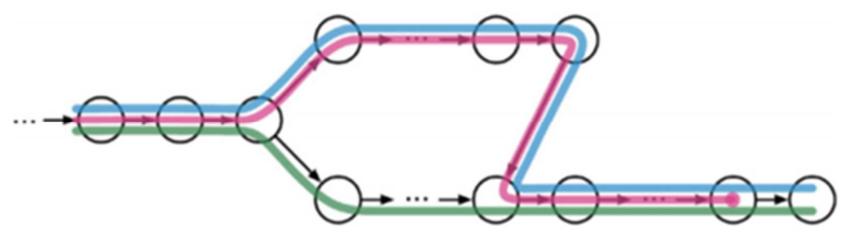

Figure 1. De Bruijn Graph.

Kallisto quant is used to quantify the abundance of transcripts.

The TPM values were calculated using the following steps:

1. Divide the read counts by the length of each transcript in kilobases, which gives you reads per kilobase (RPK).

2. Count up all the RPK values in a sample and divide this number by $1,000,000$. This is your "per million" scaling factor.

3. Divide the RPK values by the "per million" scaling factor.

The gene TPM values were obtained by averaging the transcript TPM values for that gene.

\subsection{Analysis of Intracellular Localization of Candidate Proteins}

Intracellular localization of the protein encoded by the candidate gene was analyzed by Gene Cards. Gene Cards (https://www.genecards.org/) is the database to provide the comprehensive information of the gene including gene ID, functional description, location in the genome and intracellular localization. Intracellular localization is indicated by 11 location codes (Plasma membrane, Extracellular space, Lysosome, Cytoskeleton, Endosome, Golgi Apparatus, Mitochondrion, Peroxisome, Endoplasmic reticulum, Cytosol, Nucleus), and 0-5 possibility score is assigned to each location. To sort out the gene encoding the surface protein the genes with score 5 of plasma membrane value were filtered.

\subsection{Functional Gene Network Analysis Using T-SNE}

The functional relationship of the candidate genes to Foxp3 (Treg cell-specific master transcription factor) was analyzed by the T-SNE method [11]. Including CD25, CTLA-4, CCR-4 and GITR as a positive control functional relationship of 100 candidate genes to Foxp3 was demonstrated. T-SNE is a program to visualize the functional relationship among different genes by reducing the expression value in $\mathrm{N}$ dimensions into that of 2 dimensions and mapping it in the vector domain [12]. The value of each candidate gene in $\mathrm{N}$-dimensional domain is the fold change between Th0 and Treg cells and was mapped to 2-dimensional domain using the T-SNE method and Euclidean Distance. Therefore, the gene with closer Euclidean Distance to Foxp3 indicates the closer functional relationship to the function of Treg cells.

\subsection{In vitro T Cell Activation and CD4+ T Cell Differentiation}

For the isolation of naïve $\mathrm{CD}^{+} \mathrm{T}$ cells from mice, the spleen was obtained from 7-8 weeks of age mice and the single cell suspension was prepared. Red blood cells (RBC) were removed by using RBC lysis buffer. Naïve $\mathrm{CD} 4^{+} \mathrm{T}$ cells were purified by $\mathrm{CD} 4^{+} \mathrm{CD}_{2} 2 \mathrm{~L}^{+} \mathrm{T}$ cell isolation MACS kit (Miltenyi Biotech) over 95\% purity. For naïve $\mathrm{T}$ cell activation, MACS-purified naïve T cells were activated for 72 hours with plate-bound $5 \mu \mathrm{g} / \mathrm{ml}$ of anti-CD3 $\mathrm{mAb}$ and anti-CD28 mAb (BD Biosciences) in a 96-well flat-bottom plate. For the differentiation to each subset of $\mathrm{T}$ helper cells, each condition was applied for each subset of $\mathrm{T}_{\mathrm{H}}$ cells : $\mathrm{T}_{\mathrm{H}} 1$ cells for IL-12 (10 ng/ml, anti-IL-4 antibody $(1 \mu \mathrm{g} / \mathrm{ml}), \mathrm{T}_{\mathrm{H}} 2$ cells for IL-4 $(20 \mathrm{ng} / \mathrm{ml})$, anti-IFN $\gamma$ antibody $(1 \mu \mathrm{g} / \mathrm{ml}), \mathrm{T}_{\mathrm{H}} 17$ cells for TGF $\beta 1(1 \mathrm{ng} / \mathrm{ml})$, IL-6 $(30 \mathrm{ng} / \mathrm{ml})$, anti-IFN $\gamma$ and IL-4 antibody $(1 \mu \mathrm{g} / \mathrm{ml})$ and iTreg cells for TGF $\beta 1(1 \mathrm{ng} / \mathrm{ml})$, IL-2 $(20 \mathrm{ng} / \mathrm{ml})$.

\subsection{Flow Cytometry Analysis}

The fluorescence-conjugated antibodies to stain surface antigens were anti-CD4, anti-CD25, and anti-Slc39a8. To analyze the level of Slc39a8 expression on T cells the isolated 
cells were stained with mouse anti-CD4 antibody, anti-Slc39a8-phycoerythrin antibody or anti-goat IgG control. Stained cells were analyzed with FACScalibur (Becton Dickinson) to 10,000 events and Flowjo software (Tree Star).

\subsection{TGF- $\beta$-dependent Expression of Slc39a8}

Naïve $\mathrm{CD}^{+} \mathrm{T}$ cells were activated with plate-bound anti-CD3/28 antibody and cultured with the same amount of IL-2 and various concentrations $(0-5 \mathrm{ng} / \mathrm{ml})$ of TGF- $\beta$ for the differentiation of iTreg cells. The cells with each condition were stained with anti-CD4, Slc39a8 antibody and Foxp3 antibody by the instruction of intracellular staining. Stained cells were detected by flow cytometry and analyzed by Flowjo
V10. Foxp3 was a positive control of TGF- $\beta$ induction.

\subsection{Suppression of $\mathrm{CD}^{+}$Slc39a8 ${ }^{+}$T Cells Toward Activated T Cells}

$\mathrm{CD}^{+}{ }^{+}$Slc $39 \mathrm{a}^{+} \mathrm{T}$ cells and $\mathrm{CD} 4^{+} \mathrm{Slc} 39 \mathrm{a} 8^{-} \mathrm{T}$ cells were isolated using Sony Sorter. MACS kit was used to collect naïve $\mathrm{CD} 4^{+} \mathrm{T}$ cells. Collected $\left(\sim 5 \times 10^{7}\right)$ effector T cells were stained using $0.5 \mu \mathrm{l}$ Cell Proliferation Dye eFlour ${ }^{\circledR} 670$ (Ebioscience) in $1000 \mu \mathrm{l} \mathrm{PBS}$. $\mathrm{CD}^{+} \mathrm{Slc} 39 \mathrm{a} 8^{+} \mathrm{T}$ cells or $\mathrm{CD}^{+}$Slc39a8 ${ }^{-} \mathrm{T}$ cells were cultured with eFlour ${ }^{\circledR} 670$ stained effector T cells in different ratio (1:1 and 1:4) for 72 hours. Stained cells were detected by flow cytometry and analyzed using Flowjo V10.

\section{Results}

\subsection{Integrative Bioinformatic Process of mRNA Sequencing Data About Various T Cell Subsets}

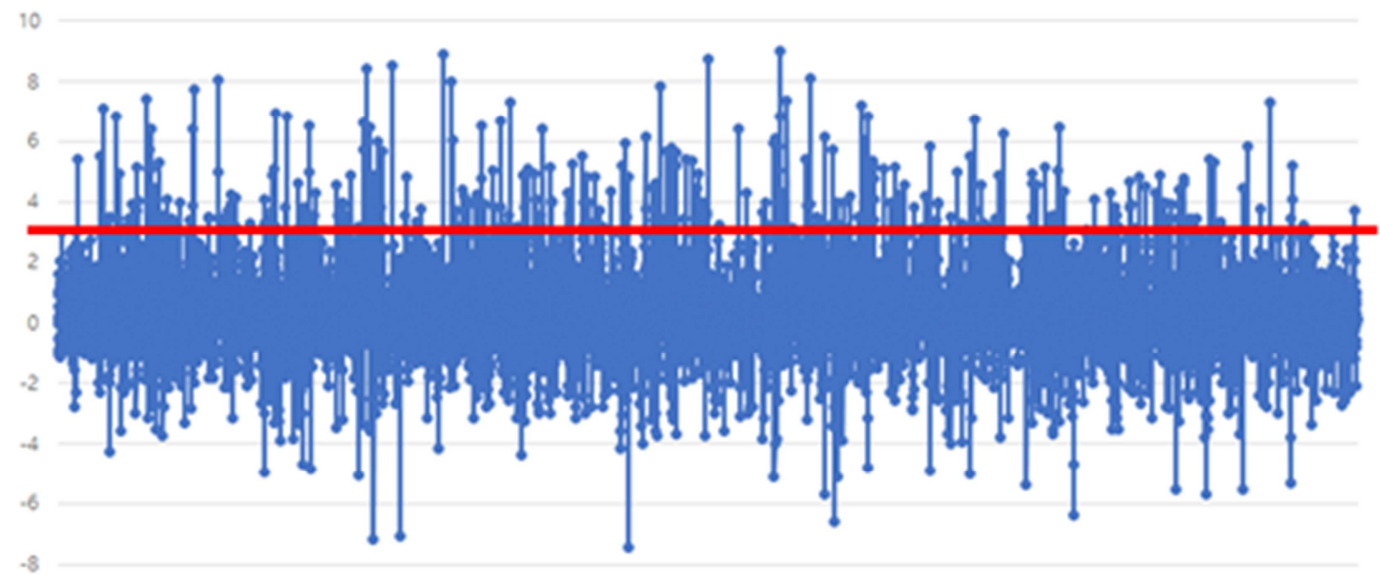

Figure 2. Fold Change Graph.
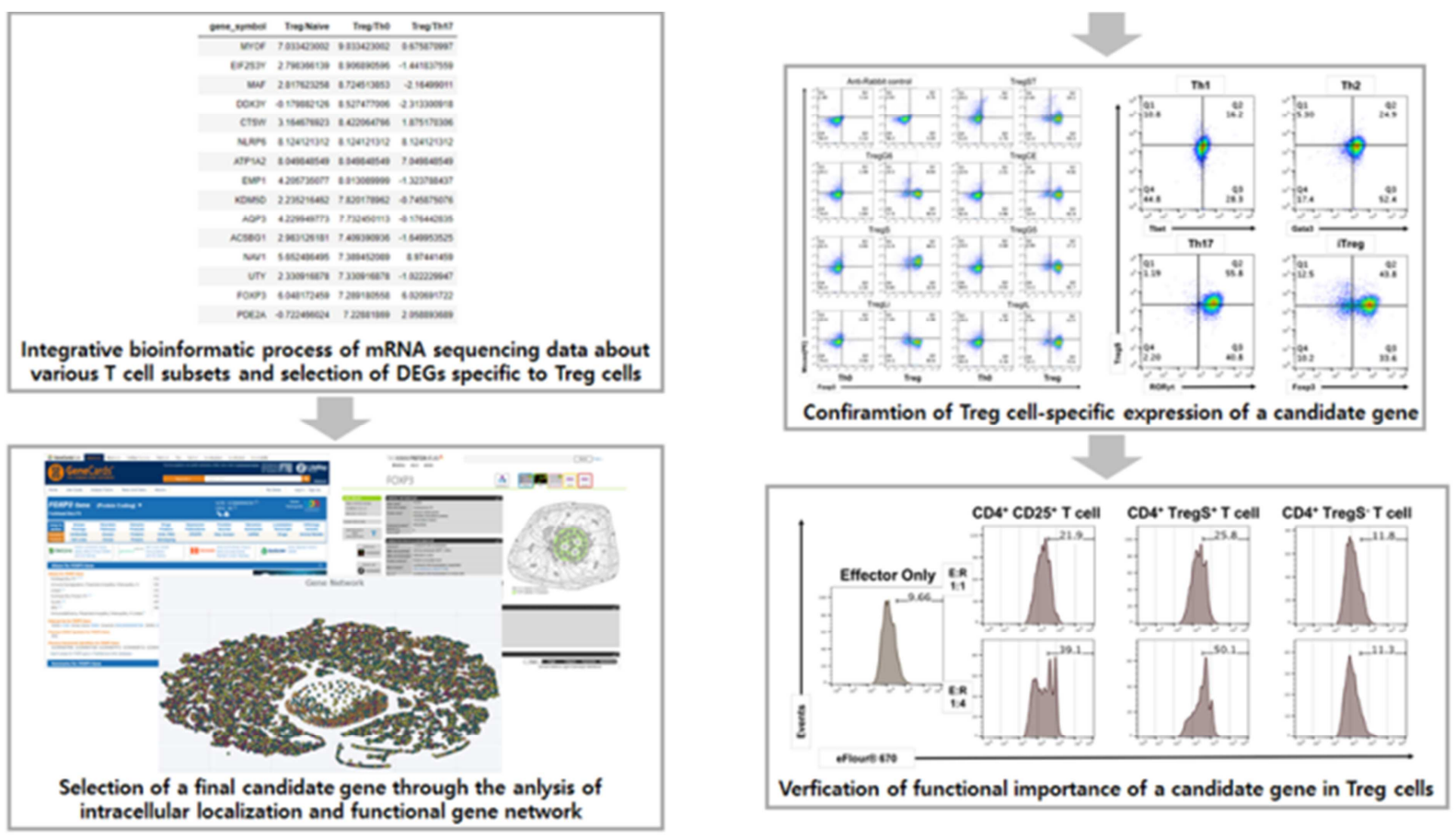

Figure 3. Workflow for identification of a novel gene specific to Treg cells. 
Treg cell-specific protein identified from the previous studies were reported to be also highly expressed in effector/activated $\mathrm{T}$ cells, which is the major therapeutic barrier to develop the novel therapeutics targeting these proteins. To identify a novel gene encoding the surface protein specific to Treg cell not to other $\mathrm{T}$ cells subsets the bioinformatic and experimental strategy was established, as shown in Figure 2. To select out the genes whose expression is highly specific to Treg cells but low in other T cell subsets, mRNA sequencing data about mouse activated $\mathrm{T}$ cells and Treg cells were prepared from Genomic Database Gene Expression Omnibus (GEO). The read count of mRNA sequencing data was converted into the normalized TPM value using Kallisto because the alignment length difference of each mRNA to its DNA sequences should be considered. Then, the top 350 DEGs specific to Treg cells out of total of 12,744 genes were collected after listing the genes by the fold change of Treg/Th0 (Figure 3).

\subsection{Selection of the Genes Encoding the Surface Protein on Treg Cells}

Among the proteins present in a various cellular compartment of Treg cells the surface protein may be the best therapeutic target molecule because monoclonal $\mathrm{Ab}$ $(\mathrm{mAb})$ highly specific to the surface protein can be easily generated using hybridoma or phage display library technology, and the development protocols for the therapeutic $\mathrm{mAb}$ drug has been well established. Using the database from Gene Cards, the intracellular localization of 350 candidate genes was examined, and 100 membrane proteins with possibility score 5 were selected. The gene such as CTLA-4, CCR4 or CD25, which was reported to encode the Treg cell-specific surface protein, was included in 100 candidate genes, suggesting that our strategy to identify the novel gene specifically expressed in Treg cells is legitimate.

\subsection{Identification of Novel Genes Specific to Treg Cells}

Transcription factor Foxp3 has been known to be the gene most specific to Treg cells and plays the critical roles for development and functions of Treg cells in vitro and in vivo. To identify the new gene highly expressed in Treg cells functional gene network analysis was also carried out in which functional or expression correlation of the candidate gene to Foxp3 is depicted as Euclidean Distance (Figure 4). Consistent with the previous findings, the function or expression of CTLA-4, CCR4 or CD25 genes are closely related to that of Foxp3.

Recently, the immune dysfunction is attributed to zinc deficiency, and thymus atrophy, immunological imbalance, and abnormality of cytokine secretion can be induced by hypozincemia [13]. Especially the genes involved in zinc homeostasis in Treg cells are poorly investigated. Among the genes functionally related to Foxp3 Slc39a8 gene encoding zinc transporter on the surface of Treg cells was chosen as a final candidate gene.

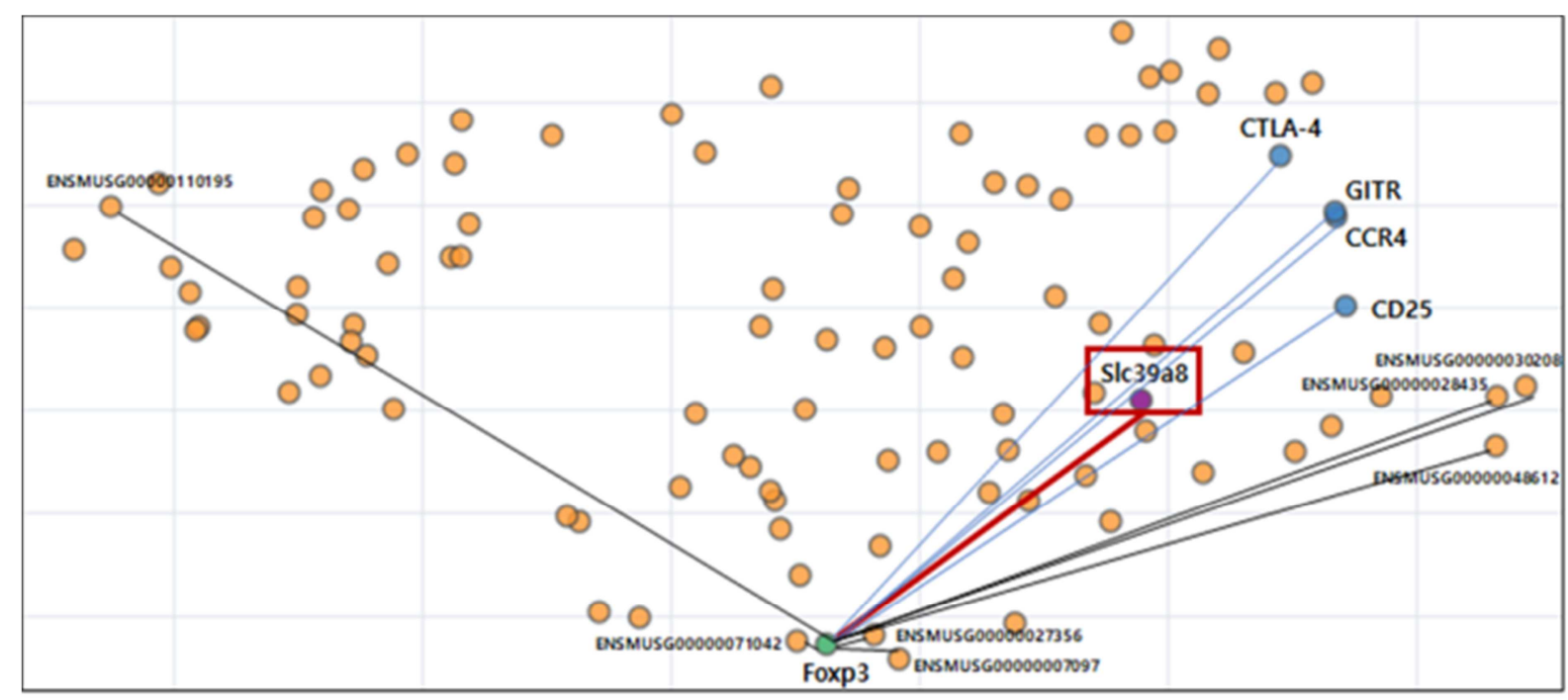

Figure 4. Functional Gene Network.

Table 1. Analysis of intercellular localization of the candidate genes.

\begin{tabular}{|c|c|c|c|c|c|c|c|c|c|c|c|}
\hline Gene & $\mathbf{P M}$ & ES & ER & CYT & LYS & MIT & GA & NUC & END & PER & CYS \\
\hline ENSMUSG00000039521 & 2 & 3 & - & 2 & 1 & 1 & 2 & 5 & - & - & 1 \\
\hline ENSMUSG00000048612 & 5 & 1 & - & 3 & - & 1 & - & 5 & 1 & 2 & 1 \\
\hline ENSMUSG00000055435 & 1 & 1 & - & 2 & - & - & - & 4 & - & 0 & 1 \\
\hline ENSMUSG00000069045 & - & - & - & - & - & - & - & - & - & - & - \\
\hline ENSMUSG00000024910 & - & 4 & 3 & - & 4 & - & - & - & - & - & - \\
\hline
\end{tabular}




\begin{tabular}{|c|c|c|c|c|c|c|c|c|c|c|c|}
\hline Gene & PM & ES & ER & CYT & LYS & MIT & GA & NUC & END & PER & CYS \\
\hline ENSMUSG00000038745 & 3 & 1 & 1 & 4 & - & 1 & - & 3 & - & 1 & 1 \\
\hline ENSMUSG00000007097 & 5 & 1 & - & - & - & - & - & - & 2 & - & - \\
\hline ENSMUSG00000030208 & 5 & 1 & - & 1 & - & - & - & 1 & - & - & - \\
\hline ENSMUSG00000056673 & - & - & - & - & - & - & - & - & - & - & - \\
\hline ENSMUSG00000028435 & 5 & 1 & - & - & - & 1 & - & 4 & - & - & 1 \\
\hline ENSMUSG00000032281 & 1 & 1 & 3 & 4 & - & 1 & - & 2 & - & 1 & 1 \\
\hline ENSMUSG00000009418 & 1 & 1 & - & 1 & - & - & - & 2 & - & - & 3 \\
\hline ENSMUSG00000068457 & - & - & - & - & - & - & - & - & - & - & - \\
\hline ENSMUSG00000110195 & 5 & 0 & 4 & 5 & - & 5 & 4 & 5 & - & 0 & - \\
\hline ENSMUSG00000031373 & - & - & - & - & - & - & - & - & - & - & - \\
\hline ENSMUSG00000041794 & - & - & - & 2 & - & - & - & - & - & - & 4 \\
\hline ENSMUSG00000021846 & 0 & - & - & 4 & - & 0 & - & 1 & - & 0 & 0 \\
\hline ENSMUSG00000071042 & 5 & - & - & 2 & - & 1 & 0 & 1 & - & - & - \\
\hline ENSMUSG00000027356 & 5 & 1 & - & 5 & - & - & - & 3 & - & - & 5 \\
\hline
\end{tabular}

PM: Plasma membrane, ES: Extracellular space, ER: Endoplasmic reticulum, CYT: Cytosol, LYS: Lysosome, MIT: Mitochondrion, GA: Golgi Apparatus, NUC: Nucleus, END: Endosome, PER: Peroxisome, CYS: Cytoskeleton.

(A)

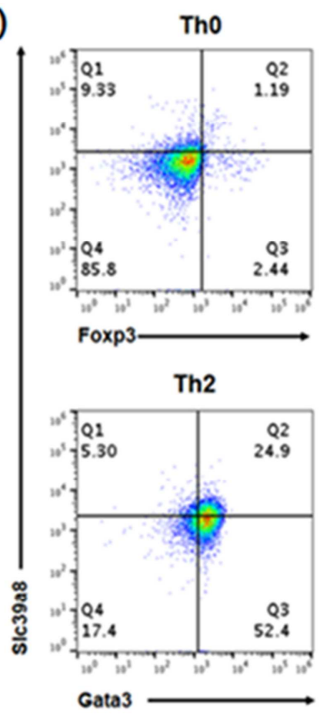

Th1

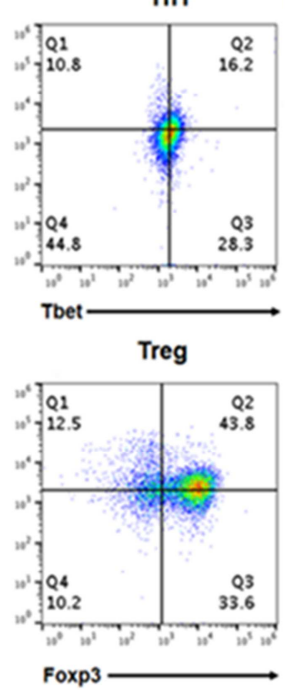

(B)

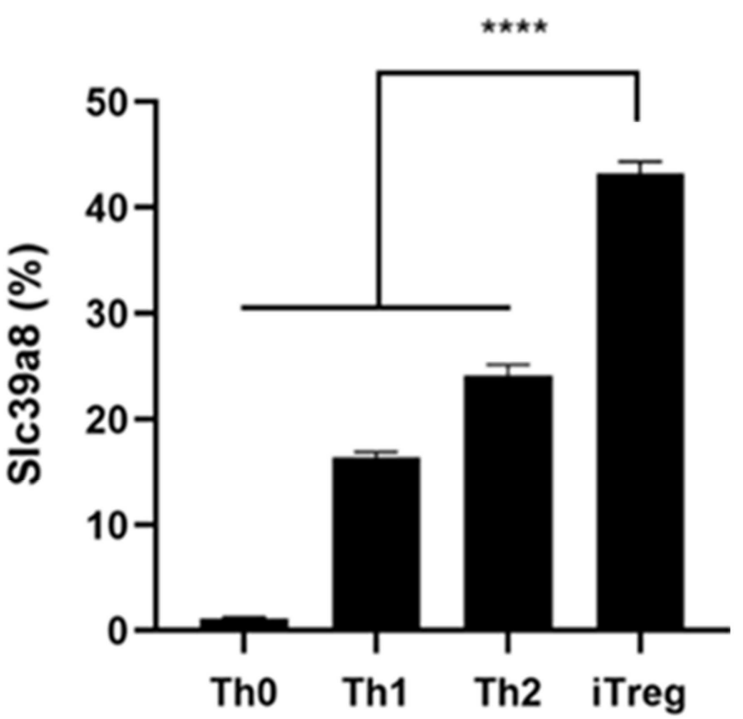

Figure 5. Treg cell-specific expression of Slc39a8.

Naïve CD4+ T cells isolated using MACS were cultured in different polarizing conditions $\left(\mathrm{T}_{\mathrm{H}} 0, \mathrm{~T}_{\mathrm{H}} 1, \mathrm{~T}_{\mathrm{H}} 2\right.$ or Treg) with plate-bound anti-CD3e and anti-CD28 antibodies for 72 hours. These $\mathrm{T}$ cell subsets were surface stained with anti-Slc39a 8 antibody followed by fixation/permeabilization. Different $\mathrm{T}$ cell subsets were stained with $\mathrm{mAb}$ specific to each transcription factor under normal intracellular staining protocols: $\mathrm{T}_{\mathrm{H}} 1$ cells with anti-Tbet $\mathrm{mAb}, \mathrm{T}_{\mathrm{H}} 2$ cells with anti-Gata3 $\mathrm{mAb}$, or Treg cells with anti-Foxp3 mAb. Stained cells were detected by flow cytometry and analyzed using Flowjo V10. Collected data were analyzed and plotted as a bar graph using Prism 8. $(* * * * \mathrm{p}<0.0001)$.

\subsection{Treg Cell-specific Expression of Slc39a8 in a TGF-ß Dependent Manner}

To investigate whether Slc39a8 protein is specifically present on the surface of Treg cells the differentiation of naive $T$ cells into various $T$ cell subsets $\left(T_{H} 0, T_{H} 1, T_{H} 2\right.$ or Treg cell) was induced by culturing naive $\mathrm{T}$ cells in the polarized condition, and identity of each $\mathrm{T}$ cell subset was confirmed by the presence of $\mathrm{T}$ cell subset transcription factor (Tbet for $\mathrm{T}_{\mathrm{H}} 1$, Gata3 for $\mathrm{T}_{\mathrm{H}} 2$ or Foxp3 for Treg cell) using flow cytometric analysis. As shown in Figure 5, the amount of Slc39a8 on the surface of Treg cell was significantly higher than that on $\mathrm{T}_{\mathrm{H}} 0, \mathrm{~T}_{\mathrm{H}} 1$ or $\mathrm{T}_{\mathrm{H}} 2$ cells. TGF- $\beta$ has been known to be the key cytokine for the immunosuppressive functions of Treg cells in autoimmune or tumor microenvironment. To examine the inducibility of Slc39a8 expression by TGF- $\beta$ naive T cells were cultured in Treg cell differentiation condition in the presence of different concentrations of TGF- $\beta$. The surface expression of Slc39a8 on Treg cells was induced by TGF- $\beta$ from $1.04 \%$ to $36.4 \%$ in a dose-dependent manner. When the induction kinetics of Slc39a8 expression was examined, the amount of Slc39a8 protein gradually reached the maximal level after 72 hours of TGF- $\beta$ incubation (Figure 6A, 6B, 6C, 6D). Taken these results together, Slc39a8 is a novel zinc transporter on the surface specific to Treg cells, and its expression is induced by TGF- $\beta$. 
(A)

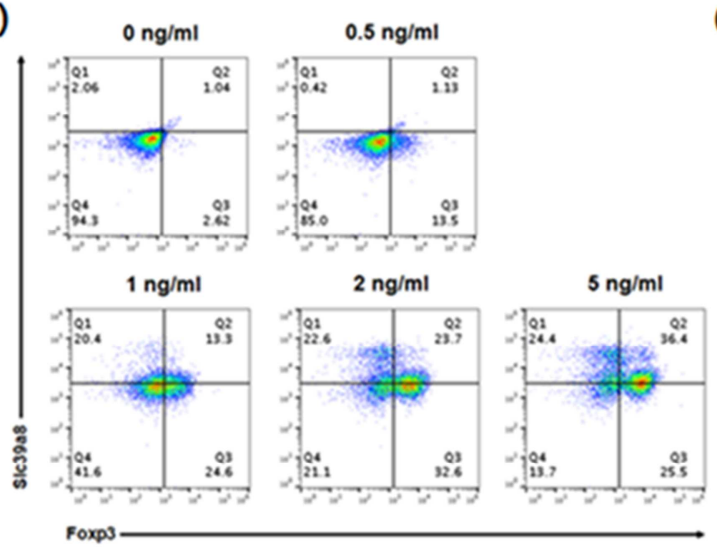

(B)

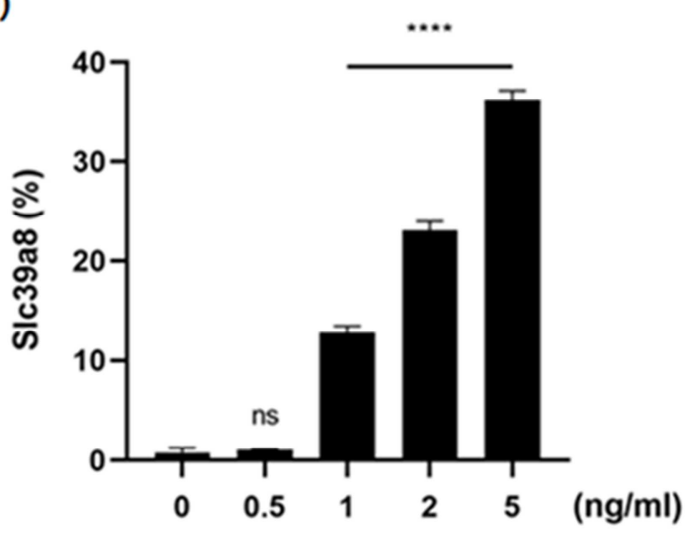

(C)

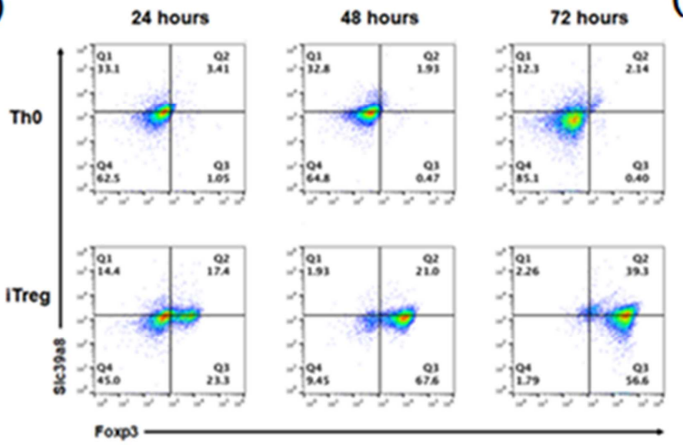

(D)

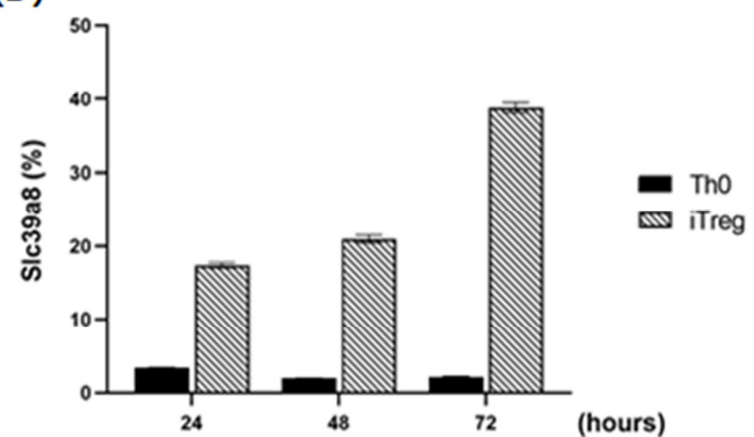

Figure 6. TGF- $\beta$-dependent expression of Slc39a8 in Treg cells.

(A), (B): Naïve CD4+ T cells isolated using MACS were cultured in different TGF- $\beta$ concentrations $(0-5 \mathrm{ng} / \mathrm{ml})$ with plate-bound anti-CD3e and anti-CD28 antibodies for 72 hours. Each well was supplemented with the same concentration $(20 \mathrm{ng} / \mathrm{ml})$ of IL-2 with iTreg polarizing conditions. The cells were stained with anti-slc39a8 antibody and anti- Foxp3 antibody under the normal surface/intracellular staining protocols. (C), (D): To examine the expression kinetics of Slc39a8 in Th0 or Treg cells naïve CD4+ T cells isolated using MACS were cultured with plate-bound anti-CD3e and anti-CD28 antibodies for 24, 48 or 72 hours. Treg cells were cultured with $5 \mathrm{ng} / \mathrm{ml} \mathrm{TGF}-\beta$ and $20 \mathrm{ng} / \mathrm{ml} \mathrm{IL-2} \mathrm{for} \mathrm{polarizing} \mathrm{conditions.} \mathrm{At} \mathrm{each} \mathrm{time} \mathrm{point,} \mathrm{cells} \mathrm{were} \mathrm{collected} \mathrm{and} \mathrm{stained} \mathrm{for} \mathrm{surface} \mathrm{Slc39a8,} \mathrm{as}$ stated above, followed by fixation/permeabilization. Cells in all three groups were stained for intracellular Foxp3 using APC conjugated antibodies. Stained cells were detected by flow cytometry and analyzed using Flowjo V10. Collected data were analyzed and plotted as a bar graph using Prism 8 . $(* * * * \mathrm{p}<0.0001)$.

\subsection{The Functional Importance of Slc39a8 for Treg Cells}

$\mathrm{CD} 4{ }^{+} \mathrm{CD} 25^{+} \mathrm{T}$ cell

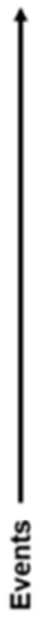

\section{CDDSCD25 Thell}
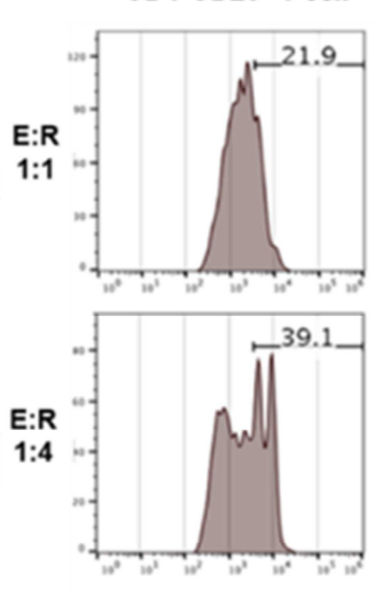

eFlour@ 670
CD4+SIc39a8+ T cell
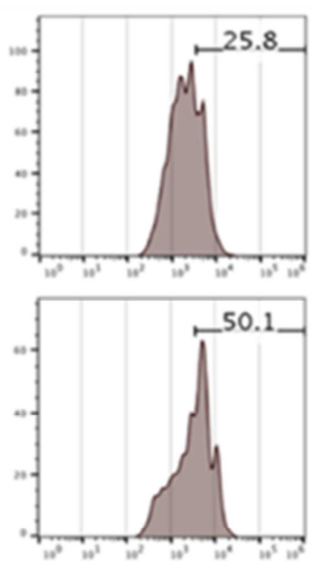

CD4+SIc39a8* T cell
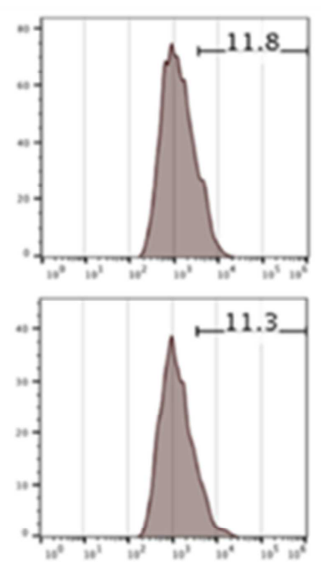

Figure 7. Suppression activity of $\mathrm{CD} 4^{+}$Slc $39 a 8^{+}$T cells.

$\mathrm{CD}^{+} \mathrm{CD} 25^{+} \mathrm{T}$ cells, $\mathrm{CD} 4^{+} \mathrm{Slc} 39 \mathrm{a} 8^{+} \mathrm{T}$ cells or $\mathrm{CD} 4^{+} \mathrm{Slc} 39 \mathrm{a} 8^{-} \mathrm{T}$ cells from the spleen of C57BL/6 female wild type mice at seven weeks of age-old were sorted by FACS and cultured with eFlour ${ }^{\circledR} 670$ stained effector $T$ cells in the different ratio (1:1 and 1:4) for 72 hours. Effector T cells were cultured under activation condition including mitomycin C treated APC and soluble anti-CD3e antibody. The suppressive activity of each sample was quantified by the percentage of cells that have undergone less than two cell division cycles. Stained cells were detected by flow cytometry and analyzed using Flowjo V10. 
To investigate whether Slc39a8 is essential for the functions of Treg cells toward the effector $\mathrm{T}$ cells in vitro $\mathrm{CD}^{+} / \mathrm{S} 1 \mathrm{c} 39 \mathrm{a} 8^{+} \mathrm{T}$ cells were purified using mAb specific to Slc39a8 protein after differentiation induction of naive $\mathrm{T}$ cells into Treg cells. Then, $\mathrm{CD}^{+} / \mathrm{Slc} 39 \mathrm{a} 8^{+} \mathrm{T}$ cells were incubated with the activated $\mathrm{T}$ cells stimulated by the immobilized anti-CD3 and anti-CD28 $\mathrm{mAbs}$ and labeled with CSFE. $\mathrm{CD}^{+} / \mathrm{CD} 25^{+} \mathrm{T}$ cells and $\mathrm{CD} 4^{+} / \mathrm{Slc} 39 \mathrm{a} 8^{-} \mathrm{T}$ cells were used as positive and negative control, respectively. As shown in Figure 7, the immunosuppressive function of $\mathrm{CD}^{+} / \mathrm{Slc} 39 \mathrm{a}^{+} \mathrm{T}$ cells was substantially better than that of $\mathrm{CD}^{+} / \mathrm{CD} 25^{+} \mathrm{T}$ cells $(39.1 \%$ vs. $50.1 \%)$, and $\mathrm{CD}^{+} / \mathrm{Slc} 39 \mathrm{a} 8^{-}$ $\mathrm{T}$ cells showed the minimal suppressive function. From these results, the Slc39a8 protein on the surface is critical for the immunosuppressive function of Treg cells.

\section{Discussion}

Treg cell expressing Foxp3, a master transcription factor essential for its development and function, is a subset of T cell which suppresses the functions of activated immune cells [14]. The reduction of the number of Treg cells or their functional defects in autoimmune micro-environment is the main cause for the induction of autoimmunity. On the other hand, the recruitment of Treg cells into the tumor micro-environment makes the anti-tumor $\mathrm{T}$ cells exhausted and nonfunctional. Although several genes encoding the surface protein on Treg cells (CTLA-4, CCR4 or CD25) have been discovered using microarray analysis or molecular techniques, these surface proteins are also substantially expressed on activated $\mathrm{T}$ cells whose function is opposite to that of Treg cells. This is why the reagents targeting these surface proteins are difficult to use in therapeutic applications.

In this study, using mRNA sequencing data about various $\mathrm{T}$ cell subsets and integrative bioinformatic approaches, Slc39a8, a novel gene exclusively specific to Treg cell, was identified, which encodes the zinc transporter present on the cell surface. In contrast to the surface markers known to be specific to Treg cells, the expression of Slc39a8 protein on the surface is highly specific to Treg cells but significantly low in other $\mathrm{T}$ cell subsets such as activated $\mathrm{T}$ cells, $\mathrm{T}_{\mathrm{H}} 1$ or $\mathrm{T}_{\mathrm{H}} 2$ cells. The suppressive potential of $\mathrm{CD}^{+} / \mathrm{Slc} 39 \mathrm{a} 8^{+} \mathrm{T}$ cells toward the activated $\mathrm{T}$ cells is better than that of $\mathrm{CD}^{+} / \mathrm{CD} 25^{+} \mathrm{T}$ cells, but $\mathrm{CD}^{+} / \mathrm{Slc} 39 \mathrm{a}^{-} \mathrm{T}$ cells did not show the immuno-suppressive functions. This result demonstrates the importance of Slc39a8 protein for the functions of Treg cells.

TGF- $\beta$ is a critical immuno-suppressive cytokine to regulate the functions of an immuno-suppressive subset of various immune cells including Treg cells [15]. As shown in Figure 6, the expression of Slc39a8 was significantly induced by TGF- $\beta$ in a dose-dependent manner, suggesting another evidence that zinc transporter Slc39a8 would play an essential role regulating zinc entry into Treg cells in autoimmune or tumor micro-environment. Several recent reports suggested that in addition to $\mathrm{Ca}^{++}$zinc could be an important second messenger involved in the signaling cascades for lymphocyte activation as well as being a structural component of many intracellular proteins [16].

\section{Conclusion}

Using integrative bioinformatics analysis zinc transporter, Slc39a8 was identified as a novel gene specific to Treg cells, whose expression is substantially low in other $\mathrm{T}$ cell subsets. $\mathrm{CD}^{+} / \mathrm{Slc} 3 \mathrm{a} 8^{+} \mathrm{T}$ cells showed significantly higher immunosuppressive activity toward effector $\mathrm{T}$ cells than $\mathrm{CD}^{+} / \mathrm{Slc} 39 \mathrm{a}^{-} \mathrm{T}$ cells, suggesting the functional importance of Slc39a8 for Treg cells. Therefore, Slc39a8 will be an important target molecule on the surface of Treg cells to develop novel therapeutics for the treatment of various autoimmune diseases or solid cancers.

\section{Acknowledgements}

This research was supported by Grobal Research Laboratory (GRL) Program through the National Research Foundation of Korea (NRF) funded by the Ministry of Science and ICT (No. 2016K1A1A2912755).

\section{References}

[1] E. G. Schmitt, C. B. Williams, Generation and function of induced regulatory T cells, Frontiers in immunology, 4 pp. 152, 2013.

[2] A. Liston, D. H. Gray, Homeostatic control of regulatory T cell diversity, Nature Reviews Immunology, 14 pp. 154-165, 2014.

[3] P. Trzonkowski, M. Bieniaszewska, J. Juścińska, A. Dobyszuk, A. Krzystyniak, N. Marek, J. Myśliwska, A. Hellmann, First-in-man clinical results of the treatment of patients with graft versus host disease with human ex vivo expanded CD4+ CD25+ CD127- T regulatory cells, Clinical immunology, 133 pp. 22-26, 2009.

[4] A. H. Sharpe, K. E. Pauken, The diverse functions of the PD1 inhibitory pathway, Nature Reviews Immunology, 18 pp. 153, 2018.

[5] X. Wang, Z. Bao, X. Zhang, F. Li, T. Lai, C. Cao, Z. Chen, W. Li, H. Shen, S. Ying, Effectiveness and safety of PD-1/PD-L1 inhibitors in the treatment of solid tumors: a systematic review and meta-analysis, Oncotarget, 8 pp. 59901-59914, 2017.

[6] L. T. Krausz, R. Bianchini, S. Ronchetti, K. Fettucciari, G. Nocentini, C. Riccardi, GITR-GITRL system, a novel player in shock and inflammation, The Scientific World Journal, $7 \mathrm{pp}$. 533-566, 2007.

[7] D. A. Knee, B. Hewes, J. L. Brogdon, Rationale for anti-GITR cancer immunotherapy, European journal of cancer, $67 \mathrm{pp}$. 1-10, 2016.

[8] N. Bray, H. Pimentel, P. Melsted et al. Near-optimal probabilistic RNA-seq quantification. Nat Biotechnol 34, pp. 525-527, 2016.

[9] P. Compeau, P. Pevzner, G. Tesler, How to apply de Bruijn graphs to genome assembly. Nat Biotechnol 29, pp. 987-991, 2011. 
[10] V. A. Schneider, T. Graves-Lindsay et al. Evaluation of GRCh38 and de novo haploid genome assemblies demonstrates the enduring quality of the reference assembly. August 2016.

[11] L. V. Maaten, G. Hinton, Visualizing Data using t-SNE. Journal of Machine Learning Research 9: pp. 2579-2605, 2008.

[12] J. A. Lee and M. Verleysen. Nonlinear dimensionality reduction. Springer, New York, NY, USA, 2007.

[13] S. Hojyo, T. Fukada, Roles of zinc signaling in the immune system, Journal of immunology research, 2016.
[14] X. Meng, J. Yang, M. Dong, K. Zhang, E. Tu, Q. Gao, W. Chen, C. Zhang, Y. Zhang, Regulatory $\mathrm{T}$ cells in cardiovascular diseases, Nature Reviews Cardiology, 13 pp. 167, 2016.

[15] E. Batlle, J. Massagué. Transforming growth factor- $\beta$ signaling in immunity and cancer. Immunity. 50. pp. 924-940, 2019.

[16] M. Yu, W. W. Lee, D. Tomar et al. Regulation of T cell receptor signaling by activation-induced zinc influx. J Exp Med. 208. pp. 775-785, 2011. 